\title{
Inappropriate admissions or inadequate discharges of frail elderly: Competing program theories and implementation challenges in an intermediate care intervention
}

\author{
Birgitte Nørgaard ${ }^{* 1}$, Helene Skjøt-Arkil ${ }^{2,3}$, Nina Nissen ${ }^{1}$, Christian Backer Mogensen ${ }^{2,3}$ \\ ${ }^{1}$ Research Unit of User Perspectives, Department of Public Health, University of Southern Denmark, Denmark \\ ${ }^{2}$ Emergency Department, Aabenraa Hospital, Hospital of Southern Jutland, Denmark \\ ${ }^{3}$ Institute of Regional Health Research, University of Southern Denmark, Denmark
}

Received: November 23, 2016

DOI: $10.5430 /$ jnep.v7n6p72
Accepted: January 12, $2017 \quad$ Online Published: January 19, 2017

URL: http://dx.doi.org/10.5430/jnep.v7n6p72

\begin{abstract}
Intermediate care interventions are increasingly being implemented in the health services to avoid hospitalizing elderly frail patients with complex medical issues, often referred to as inappropriate or unwarranted admissions. This paper presents a theory-based stakeholder evaluation of an intervention involving hospitals, community care and general practitioners (GPs) in a Danish region with the overall objective to reduce the number of (inappropriate) hospital admissions for the frail elderly of 65 years or older. In a controlled study design elderly acutely ill patients were randomized to care and treatment either by a district nursing team or in an emergency department (ED) - both interventions with a 48-hour time limit. The district nursing teams were given access to various telemedicine solutions. In the programme theory analysis the stakeholders' normative theories, situation theories and causal theories were studied. Competing programme theories and barriers and facilitators were identified. Data were collected in interviews with stakeholders (managers, nurses, hospital physicians and GPs) and from the literature. The intervention included a regional hospital, four municipalities and 166 GPs servicing a mixed urban and rural region in Denmark. Four district nursing teams, eight GPs, three hospital physicians and two project managers were interviewed between January and March 2015. The stakeholder's programme theories were both concordant and competing; the GPs in particular were sceptical of the purported objective of reducing the number of inappropriate hospital admissions; they would rather see a reduction in the number of inappropriate hospital discharges. Our results indicate a compromised implementation process.
\end{abstract}

Key Words: Intermediate care, Interventions, Theory-based stakeholder evaluation, Elderly care

\section{INTRODUCTION}

There is a growing body of evidence that suboptimal hospital care and treatment of frail elderly patients with complex medical issues are caused by short and compressed admissions $^{[1,2]}$ and by the loss of information in the transition from hospital to community care. ${ }^{[3]}$ These problems are increasingly addressed through new forms of health care delivery, such as intermediate care interventions, traditionally targeting elderly people. ${ }^{[4]}$ Intermediate care offers temporary treatment and care aiming at facilitating the transition

*Correspondence: Birgitte Nørgaard; Email: binorgaard@ health.sdu.dk; Address: Institute of Public Health, University of Southern Denmark, J.B. Winsløws Vej 9B, DK-5000 Odense, Denmark. 
from hospital to home or to avoid admissions, according to international consensus on the definition of intermediate care. ${ }^{[5]}$ Despite this definition, the concept covers a wide range of interventions and target groups ${ }^{[4]}$ the effects of intermediate care intervention are thus difficult to measure and the results ambiguous. While some studies have reported substantial challenges in the implementation process, ${ }^{[6]}$ others have found significant decreases, not only in admission rates, costs and admission lengths, ${ }^{[7-9]}$ but also in readmission rates. ${ }^{[10]}$ A number of other studies, despite findings of increased costs, ${ }^{[11,12]}$ report no significant impact on admission ${ }^{[1,2,13]}$ and readmission rates. ${ }^{[14,15]}$ The inconsistent findings may be due to the fact that the care of frail elderly citizens has multiple stakeholders, with different jurisdictions (e.g. community care, hospitals and general practitioners (GPs)) and involves several professions and multiple institutions (e.g. district nurses, emergency departments (EDs), day hospitals, nursing homes, day centres).$^{[16]}$

This paper presents a theory-based stakeholder evaluation of an intermediate care intervention. Attention points for further implementation or for developing a generic model for intermediate care are presented.

\section{Methods-The ACCESS-PROJECT}

The evaluation concerns the ACCESS project (Acute Combined Care for Seniors in South Jutland). The project was implemented in a mixed urban and rural district in Denmark from November 2013 to February 2015 and involved a regional hospital (with three branches located across the catchment area: a day hospital, a specialist hospital and an emergency hospital), 166 self-employed GPs and four municipalities (i.e., their district nursing services, nursing homes and day centres).

\subsection{Setting and intervention}

Overall, the ACCESS project aimed to reduce hospital admissions for frail elderly citizens of 65 years or older with acute medical illness requiring immediate treatment and care. A number of outcome measures were included, among them admission rates, mortality, mental health, physical function and patient satisfaction (results published elsewhere). The patients were identified either by GPs or district nurses and randomized to treatment either by the GP in collaboration with municipal nursing services or by the hospital specialist in internal medicine in collaboration with municipal nursing services. Both interventions were limited to 48 hours. The municipal district nursing teams were given an eight-hour training course in emergency medicine and had access to various telemedicine solutions, including a telephone hotline and, if needed, a video communication system with an ED consul- tant, and to point-of-care technology for the assessment of vital blood parameters. A website provided the project guidelines with regard to identification and inclusion of patients, algorithms for triage and vital blood parameters, information on included patients and informed consent procedures, instructions for telemedicine solutions, and special agreements with the GP's regarding payment and responsibility in case of non-admission.

The project was implemented simultaneously in all four municipalities that constitute the regional hospital's catchment area.

\subsection{ACCESS - input-conversion-output-outcome}

The project was based on an agreement on the desirability of avoiding as far as possible the hospitalization of frail elderly citizens and the assumption that new and targeted alternatives would decrease the number of acute admissions and re-admissions. The target group was elderly of 65 years or older with acute medical illness requiring immediate medical attention of a kind that could be handled without hospital admission, such as intravenous fluid therapy, intravenous antibiotic therapy or intensified monitoring of vital blood parameters, blood pressure, pulse and oxygen saturation. A number of steps were taken to facilitate the intervention:

(1) early identification and upscaled monitoring by GPs and district nurses

(2) training of district nurses in emergency care

(3) expanded inter-sectoral collaboration

(4) effective telemedicine solutions and communication structures

(5) training the district nurses' in emergency medicine

(6) treatment in patients' own home.

\subsection{Formal approval}

The RCT was approved by the Regional Scientific Ethical Committees of Southern Denmark (no: S-20130022) in autumn 2013 and the Danish Data Protection Agency (no: 200858-0035), ClinicalTrial.gov Identifier: NCT02422849. The work was supported by the Danish Health and Medicines Authority (no: J.4-1611-4/3).

\subsection{The evaluation design}

The evaluation was carried out using a programme theory framework called theory-based stakeholder evaluation (TSE) as described by Hansen and Vedung. ${ }^{[17]}$ The framework describes the stakeholders' programme theory for the specific intervention including their 1) situation theory; 2) normative theory and 3) causal theory. Situation theory refers to the stakeholders' notions of the contexts without or before the intervention, including their thinking on the relevance of 
any invention. Normative theory describes the stakeholders' values, norms, ideals and goals for the preferable situation, whereas causal theory concerns their notions of the impact of the intervention and the problems leading to an intervention. We offer separate descriptions of each stakeholder groups' programme theories and the overall programme theory underlying the intervention.

Hansen \& Vedung recommend a five-step approach to theorybased stakeholder evaluations: 1) reconstruction of the underlying programme theory, 2) identification of relevant stakeholders, 3) inclusion or exclusion of stakeholder groups, 4) reconstruction of stakeholders' programme theories and 5) comparison of programme theories. ${ }^{[17]}$

\subsection{Data collection and participants}

In order to describe the programme theory underlying the intervention (Step 1), the project managers were interviewed and data were collected by reviewing written sources, such as the project's website, the protocol and the project guidelines.

Because of the variation in interventions in the four municipalities, all four district nursing teams and two GPs from each municipality were included. We furthermore included medical doctors from the hospital's ED, a specialist hospital and a day hospital (Steps 2 and 3). The stakeholder groups' programme theories were uncovered in interviews (Step 4). To ensure maximal coverage of the most relevant topics, a semi-structured interview guide was prepared in advance. ${ }^{[18]}$ The guide was prepared with a view to the document review and the literature review and was subsequently adjusted to the specific stakeholder groups. Group interviews were conducted with the four district nursing teams (ten persons), two hospital physicians and the project leaders (two persons), while eight GPs and one hospital physician were interviewed individually.

A total of 23 professionals were interviewed. All interviews were carried out from January 26th to March 5th 2015 using a recording device.

The identification of the individual stakeholder group's programme theories enabled us to analyse them with respect to their agreement and coherence or conflicting (Step 5). This furthermore uncovered any conflicts, barriers and facilitators for implementation and achievement of objectives.

\subsection{Information of participants}

All interviewees were contacted by email and informed about the study and the nature of their contribution. All information was treated in strictest confidence and the participants' anonymity ensured.

\subsection{Data analysis}

The interviews were transcribed verbatim, excluding occasional exclamations and unclear or irrelevant passages. In the interpretation of data, priority was given to what the stakeholders found important, rather to what they found interesting or what was mentioned repeatedly. The data were subsequently structured according to the analysis tools: a) application of a principle of reason; b) theories structured in a tripartite scheme, and c) raw theories organized according to the extended system model (input-conversion-outputoutcome). ${ }^{[17]}$

To enhance the rigour of the process and findings we thoroughly followed the methodical steps recommend by Hansen and Vedung ${ }^{[17]}$ and the standards for reporting qualitative research (SRQR) summarized by O'Brien et al. ${ }^{[19]}$

The programme theory evaluation was approved by the project leaders, the hospital managers and the four chief executives from the included municipalities. No further formal approval is required by Danish legislation.

\section{Findings}

\subsection{Programme theory underlying the ACCESS project: decreased admission rate for frail elderly}

The project aimed at reducing the large number of short admissions (of fewer than 48 hours) of frail elderly citizens. Reports from GPs to the hospital had indicated little benefit to the patients from hospitalization; although they may have been diagnosed, the treatment was often found to be incomplete and put patients at high risk for delirium or hospital infection. Delayed communication between hospital and GPs moreover hampered the GPs' follow-up of treatment after discharge.

With its many stakeholders, the complexity of the project was evident from the design phase. As the project was funded by the Danish Health and Medicines Authority, several factors were predetermined, such as the overall aim to reduce emergency admissions in an inter-sectoral approach, the project's target group (senior citizens 65+) and the telemedicine initiatives. Furthermore, both GPs and district nurses had been involved in drawing up recommendations of appropriate interventions if the number of admissions for the specific target group should be minimized, including quick access to diagnostics and specialist skills, and backup-supported pointof-care technology for more advanced care and treatment in the patients' own home. The primary endpoint, a decreased admission rate, was nevertheless considered a fragile endpoint.

The project thus corroborated the current political trends and was based on existing district services. Furthermore, there 
was an economic incentive for the municipalities as they could save up to DKK 14,000 (Approximately USD\$2,100 or $€ 1,900$.) per avoided hospitalization.

Several barriers to implementation were expected. Firstly, the highly heterogeneous target group (its age span, multimorbidity and varying quality of the social network essential to managing acute illness in the home), which was suspected to affect the accuracy of the intervention, and thus the effect of the project. Practical issues were foreseen to present barriers (e.g., the placement of responsibility for insertion of intravenous cannulas; delivery, collection and payment for medicine and intravenous fluids; and for follow-up on blood tests). Not least, the GPs' position to abstain from admission of acutely ill patients could challenge the project as the GPs in case of non-admission would take over or keep the responsibility for patients who would otherwise have been hospitalized. Yet, the most overwhelming barrier was supposed to be GPs' reluctance to join the project and thereby cause a difficult and hampered inclusion of patients. A further complication was introduced by a prolonged conflict between GPs and the Danish Regions, which prevented the former from participation in the design phase of the project. They joined the group a month before project start.

\subsection{GPs' programme theory: hospital discharges or readmissions}

The GPs' general position on the referral of senior citizens to hospital treatment appeared to be influenced by their experience that strong advocacy was required. They conceded that inadequate diagnostic tools could be a factor in a decision to suggest hospitalization. The majority of GPs agreed that hospitalization should be avoided as far as possible due to the risk of derangement and hospital infection. On the other hand, they expressed a widespread scepticism regarding a reduction in referral rates as an appropriate professional aim; they voiced concern that a political agenda could result in less optimal treatment of elderly citizens solely caused by their age. In their opinion, their referral of elderly citizens was an accurate reflection of the need, and they advocated a change of focus to what they called inappropriate discharges that contributed to frequent readmissions - or inevitable admissions. The GPs' had seen a development of hospitals into fast-track institutions with low-level care and information, which they considered a poor match with the multiple and complex needs of their elderly patients. In their view, this constituted "a hospital project", an attempt to shift tasks away from hospitals to GPs and district nurses. They indicated having had difficulties with identifying relevant patients for the project as they felt they would often be either too well or too ill for inclusion. In the latter case, they deemed the

Published by Sciedu Press randomization to treatment unethical as the patients may be cognitively affected by their condition.

The GPs emphasized their collaboration with district nurses as a key factor in treating citizens with complex problems and needs without hospitalization. Although they did not see the increased responsibilities following from the project as a barrier to their participation, they expressed concern about the increased burden of supervision of district nurses and ward rounds in nursing homes or the patients' homes. Point-of-care technology was seen as an important factor in avoiding admissions, while uncertainty about financing of medications was considered an obstacle. The telemedicine solution was deemed irrelevant, mainly because of its complexity and counter-intuitive user interface.

The GPs insisted that a successful transferral of traditional hospital task to community care would require further collaboration with district nurses and more nursing home places accompanied by adequate training of staff. For maintenance of the quality of their own services, more staff with better trained nursing assistance would be needed. Access to diagnostic tools, fast diagnostic results (e.g. blood tests, $\mathrm{X}$-rays), and specialist support from the ED was also considered necessary. Furthermore, adequate resources, seamless inter-sectoral collaboration and the fact that treatment was completed before discharge in cases of hospitalization were also considered prerequisites for an increased admission rate for frail elderly.

\subsection{Medical specialists' programme theory: a buffer for emergency departments}

Despite their sceptical view of what they considered the political rationale of the ACCESS project, with its overall aim of reducing hospitalization and increasing outpatient activity, the medical staff at the hospital nevertheless found that GPs referral of elderly patients was not always substantiated, possibly because of poor communication with the hospital. They believed that better communication would help reduce acute admissions of the frail elderly, whereas hasty discharges and delayed discharge summaries contributed to an increased re-admission rate. The hospital physicians hoped that the project would provide "buffer capacity" for the ED and thus primarily benefit the hospital, whose reduced bed numbers had put the ED under constant pressure. The risk of hospital infections and delirium was also mentioned as a motivation for minimizing the number of admissions.

Although they fully understood the wish of elderly frail citizens to remain in their own homes and avoid hospitalization, even in case of acute illness, the hospital physicians were sceptical of the possibility of identifying the project's target 
group as they found this group tends to be either so ill that hospitalization is necessary or so well-functioning that they do not need intermediate care.

The group considered the randomization to treatment as a liability, as extra tasks such as inclusion and care and treatment would mean extra work for them. Likewise, they were concerned that the GPs would be responsible for patients who would otherwise have been hospitalized and also the unavoidable difficulties of cross-organizational collaboration between the project's stakeholders (district nurses, hospital doctors and GPs). The included type of patients in the project were perceived as having relevant problems, although they might have been too old and with too many co-morbidities to optimally benefit from the intermediate care interventions and furthermore, they were cognitively affected and thus may not have been able to give informed consent to randomization.

The interface of the telemedicine solution was considered counterintuitive and too complex for practical use. The consultants likewise rejected reliance on video imagery as unacceptable in the assessment of acutely ill patients.

According to the hospital physicians, success in reducing the admission rate for the target group would require better telephone supervision of GPs, an increased outpatient capacity and faster diagnostic tools for GPs. Additional training of district nurses in emergency care was also deemed necessary. They saw the changes involved in referral practice rested with GPs rather than with the hospitals.

\subsection{District nurses' programme theory: causes of read- missions}

Overall, the district nurses found that inter-sectoral collaboration was well-functioning but mentioned the lack of followup plans after discharge and GPs' tendency to admit elderly citizens (too) quickly. They consistently stressed the desirability of avoiding hospitalization of elderly citizens due to the risk of delirium and hospital infections, but also because in their view hospital care was poor, with overcrowded wards and little time for adequate care for the frail elderly patients. The nurses agreed with other groups in seeing the municipalities' economic incentive to avoid hospitalizations as a major driver behind the project.

There were varying views as to the suitability of the target group for the ACCESS interventions. Some found the included patients' conditions too poor for real benefit whereas others were convinced that the interventions had contributed to reducing hospitalization. In general, the district nurses considered themselves as well prepared for the interventions. Nevertheless, in their experience, the project faced practi- cal challenges connected with responsibility for inserting intravenous cannulas, payment for transportation of patients, and the lack of access to GPs and adequate nursing skills through evenings, nights and weekends. These practical issues, combined with GPs' sometimes poorly founded reluctance towards the project were seen as barriers to success. The task of informing GPs, health care assistants, as well as citizens and their families about the project was felt as a major burden, which they found stressful and challenging. On the other hand, they emphasized the well-functioning collaboration with the GPs and the GPs commitment when patients had been included.

The group expressed scepticism towards the project's randomization design as they considered it unethical to ask an elderly patient to join the project at a time of acute illness. They related several cases in which the risk of hospitalization by randomization had made citizens refuse participation. They shared the view of other groups on the telemedicine solution, stressing that only a simple and intuitive interface would be capable of contributing to reducing the referral admission rate.

Figure 1 summarizes stakeholders' programme theories.

\subsection{Concordant or conflicting programme theories}

A comparison across the stakeholder groups shows overall agreement with respect to normative theories and causal theories. Although their situation theories exhibit some agreement, there are conflicting programme theories between the stakeholder groups. In assessing the relevance of the intervention, the stakeholders generally focused on the risks involved (delirium and infection) in the hospitalization of elderly frail citizens on whose inappropriateness which they were in broad agreement with. In general, collaboration between GPs and district nurses was viewed as excellent and in need of no changes, whereas collaboration between hospitals and GPs and between hospitals and district nurses needed improvement, in particular with regard to post-discharge follow-up plans, diagnostic tools for GPs and ED specialist supervision. Overall, the stakeholders agreed on seeing the project as politically motivated and primarily driven by hospital interests. However, the terminology of "hospital admissions" and "inappropriate discharges" was highly contentious. In the GPs' perspective, hospital services are often poorly matched to elderly citizens' multiple and complex needs; a fact that causes inappropriate discharges and thus inevitable re-admissions. The stakeholders were in overall agreement on the aim of minimizing the hospitalization of frail elderly citizens. However, competing programme theories were found in relation to the key issue of the project, the inappropriate admissions of frail elderly to hospital. 
Overall, the stakeholders' causal theories were found to be in agreement. Reductions in admission rates for the frail elderly would require adequate professional resources, including ad- equate nursing skills and more GPs. Furthermore, better and faster diagnostic tools for GPs would be needed, as well as supervision and simple and intuitive IT solutions.

\begin{tabular}{|c|c|c|c|c|}
\hline & $\begin{array}{l}\text { Embedded in the } \\
\text { ACCESS project }\end{array}$ & GPs & Medical doctors/hospital & District nurses \\
\hline 范 & $\begin{array}{l}\text { - multiple, short } \\
\text { admissions of frail elderly } \\
\text { - risk of delirium and } \\
\text { hospital infections during } \\
\text { hospitalization } \\
\text { - economic incentive for } \\
\text { municipalities when } \\
\text { admission rates are } \\
\text { decreased }\end{array}$ & $\begin{array}{l}\text { - challenging to admit frail } \\
\text { elderly } \\
\text { - hospitalization can be necessary } \\
\text { - inappropriate discharges } \\
\text { - inevitable admission } \\
\text { - risk of delirium and hospital } \\
\text { infections during hospitalization } \\
\text { - hospitals are evolved fast track } \\
\text { institutions with low-level care } \\
\text { and information }\end{array}$ & $\begin{array}{l}\text { - emergency department are } \\
\text { constantly under pressure and } \\
\text { have reduced bed masses } \\
\text { - risk of delirium and hospital } \\
\text { infections during hospitalization } \\
\text { - poor supervision and poor } \\
\text { diagnostic tools for GPs }\end{array}$ & $\begin{array}{l}\text { - lack of follow-up plan after } \\
\text { discharge } \\
\text { - (too) quick admissions of frail } \\
\text { elderly } \\
\text { - risk of delirium and hospital } \\
\text { infection during hospitalization } \\
\text { - low-level care and lack of time in } \\
\text { emergency departments }\end{array}$ \\
\hline 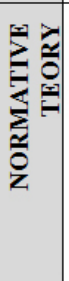 & $\begin{array}{l}\text { - decreased admission rate } \\
\text { for frail elderly } \\
\text {-improved inter-sectoral } \\
\text { cooperation }\end{array}$ & $\begin{array}{l}\text { - a political agenda } \\
\text { - more optimal discharges }\end{array}$ & $\begin{array}{l}\text { - buffer capacity for the } \\
\text { emergency department } \\
\text { - a political agenda } \\
\text { - GPs should change their } \\
\text { practice } \\
\text { - a benefit for the emergency } \\
\text { departments } \\
\text { - elderly citizens would prefer to } \\
\text { avoid hospitalization }\end{array}$ & $\begin{array}{l}\text { - cost savings for municipalities } \\
\text { - better collaboration with GP's } \\
\text { - more care and treatment can be } \\
\text { conducted outside hospitals } \\
\text { - elderly citizens would prefer to } \\
\text { avoid hospitalization }\end{array}$ \\
\hline 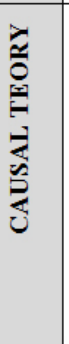 & $\begin{array}{l}\text { - intermediate care } \\
\text { interventions } \\
\text { - training of district nurses } \\
\text { in emergency care } \\
\text { - better diagnostic tools for } \\
\text { GPs } \\
\text { - supervision of GPs and } \\
\text { district nurses by } \\
\text { emergency specialist from } \\
\text { hospital } \\
\text { - supportive telemedicine }\end{array}$ & $\begin{array}{l}\text { - better diagnostic tools } \\
\text { - well-functioning inter-sectoral } \\
\text { cooperation } \\
\text { - access to adequate nursing skills } \\
\text { - adequate resources } \\
\text { - supervision by emergency } \\
\text { specialist from hospital }\end{array}$ & $\begin{array}{l}\text { - training of district nurses } \\
\text { - supervision of GPs and district } \\
\text { nurses by emergency specialist } \\
\text { from hospital } \\
\text { - supportive telemedicine } \\
\text { - better diagnostic tools for GPs }\end{array}$ & $\begin{array}{l}\text { - not too ill patients } \\
\text { - adequate nursing skills, also } \\
\text { through evenings, nights and } \\
\text { weekends } \\
\text { - knowledge about the project } \\
\text { - simple and intuitive telemedicine }\end{array}$ \\
\hline
\end{tabular}

Figure 1. A three-step-description of program theories presented by stakeholder group

\subsection{Conflicts, barriers and facilitators to the success of the ACCESS-project}

Our examination of the stakeholders' programme theories indicated a number of prerequisites for the success of the ACCESS project and potential conflict areas or barriers to implementation. All parties agreed that motivation and commitment would be essential, while a sense of exclusion from involvement in the project development would pose a distinct barrier, particularly in relation to GPs. The pronounced scepticism of this group towards the basic tenet of the project, that inappropriate referrals were a significant problem, had thus proved to be a major barrier. The existing pressure on their time and the lack of relevant competences had also presented significant barriers to implementation.

The success of the project would also depend on factors such as:

- Addressing the problems of time and competences that the increased responsibility involved for GPs in case of non-hospitalization;

- Identifying the optimal target group for the project, which proved to be a challenge, especially for GPs;
- Simple and intuitive IT solutions;

- Adequate information to citizens on the opportunities and consequences of participation, including randomization and payment;

- Informing all stakeholders about the project's elements;

- Clarifying practical issues prior to implementation.

Finally, the project design appeared to be a barrier for implementation. While the project managers had been convinced that all stakeholders were included in the process, the GPs generally felt excluded from the project planning as they were not represented during its crucial planning phase.

\section{Discussion}

As an intermediate care intervention the ACCESS project is representative of recent attempts to reduce the number of "inappropriate" hospital admissions for frail elderly citizens. Although there is no internationally agreed definition of intermediate care, it appears that the interventions are typically fostered by policy-makers. ${ }^{[5]}$

Such interventions typically involve transitory care provision 
between hospitals and care centres and the citizens' homes that aims to reduce admission rates and admission length. ${ }^{[20]}$ The first known intermediate care interventions emerged around year 2000, as a response to studies showing an increase in the number of hospitalizations of frail elderly as a consequence of inadequate prevention and rehabilitation. ${ }^{[3]}$ Intermediate care interventions are characterized by: 1) being aimed at citizens who otherwise face unnecessarily long hospital stays or inappropriate admissions, 2) thorough assessment and structured individual treatment planning, 3) aiming at increased independence, 4) being temporary, typically lasting between one week and six weeks, and 5) involving multiple health professions with shared access to medical records (Ibid.).

Despite this attempt to define intermediate care, the concept still covers a wide range of interventions, e.g. such that aim at preventing hospitalization and the facilitation of the transition from hospital to home. Also the chronically ill or disabled may be targeted. ${ }^{[4,20]}$

The findings concerning the effect of intermediate care interventions are ambiguous. Whereas two British studies failed to detect a reduction in acute admissions or fewer (re-) admissions to hospital or other institutions, ${ }^{[1,2,13]}$ other studies have found significantly fewer acute admissions, reduced admission length and reduced cost after intermediate care interventions ${ }^{[7,8]}$ and better cost efficiency when compared to standard treatment. ${ }^{[9]}$ Others, however, were unable to detect significant differences in the total cost for intermediate care and hospitalization. ${ }^{[11,12]}$ The difficulties in establishing evidence for such a broad concept are further underpinned by Danish and German studies of readmissions or transfers to residential care. ${ }^{[14,15]}$ In comparison to standard treatment, none but a single Danish study found significantly fewer readmissions after an intermediate care intervention. ${ }^{[10]}$ Another study focusing on implementation challenges, identified problems with recruiting and retaining qualified professionals, inadequate funding, lack of support and involvement from GPs, lack of knowledge about the intervention and lack of integration and coordination of services. ${ }^{[6]}$

This theory-based stakeholder evaluation has shown that not all outcome assumptions of the ACCESS project were met, probably due to erroneous implementation. Furthermore, the implementation was seriously challenged by the lack of concord between the stakeholders' understandings of the project's key concept of inappropriate admissions.

The discrepancy between stakeholder group perceptions should also be noted. While the project offered the very of tools that were required by the GPs in implementing the ACCESS project's aim, their implementation rendered them ineffective or meaningless in the view of GPs. These concerned better diagnostic tools, improved inter-sectoral collaboration, improved nursing skills and supervision by hospital emergency specialists.

The stakeholders thus seem to be ambivalent towards the ACCESS project: while on the one hand they agreed on the aim of avoiding hospitalization of the frail elderly, they were on the other hand distinctly sceptical towards what they saw as a political agenda underlying the project.

The theory-based stakeholder analysis identified a number of attention points that would be crucial for the success of future intermediate care projects or for developing a generic model for intermediate care:

- Ownership and anchoring among all key stakeholders through the establishment of shared goals

- Local project leadership

- Adequate and continuous information and support regarding telemedicine

- Unambiguous agreements regarding responsibility, time and resources in relation to specific actions

- Telemedicine solutions should be meaningful, intuitive and easy to use

- Clarification of practical matters, including medical equipment, medicines, user fees, transport

- Clearly defined target group, i.e. not too comorbid and socially vulnerable to possible benefit from the intervention

Finally, it is recommended that a feasibility study is conducted prior to large-scale implementation.

\section{CONFlicts OF InTEREST Disclosure}

The authors declare that there is no conflict of interest.

\section{REFERENCES}

[1] Young J, et al. A prospective baseline study of frail older people before the introduction of an intermediate care service. Health Soc Care Community. 2005; 13(4): 307-12. PMid:15969701 https: //doi.org/10.1111/j.1365-2524.2005.00555.x
[2] Young JB, et al. A whole system study of intermediate care services for older people. Age Ageing. 2005; 34(6): 577-83. PMid:16267182 https://doi.org/10.1093/ageing/afi179

[3] Petch A. Intermediate care. What do we know about older people's experiences?, J.R. Foundation, Editor. 2003. University of Glasgow: 
York. p. 1-37.

[4] Nancarrow SA, Moran AM, Parker SG. Understanding service context: development of a service pro forma to describe and measure elderly peoples' community and intermediate care services. Health \& Social Care in the Community. 2009; 17(5): 434-446. PMid:19456903 https://doi.org/10.1111/j.1365-2524.20 09.00846. $\mathrm{x}$

[5] Melis RJF, et al. What is intermediate care?: An international consensus on what constitutes intermediate care is needed. BMJ : British Medical Journal. 2004; 329(7462): 360-361. PMid:15310588 https://doi.org/10.1136/bmj.329.7462.360

[6] Regen E, et al. Challenges, benefits and weaknesses of intermediate care: results from five UK case study sites. Health \& Social Care in the Community. 2008; 16(6): 629-637. PMid:18484975 https://doi.org/10.1111/j.1365-2524.2008.00788.x

[7] Baker A, et al. Anticipatory care planning and integration: a primary care pilot study aimed at reducing unplanned hospitalisation. Br J Gen Pract. 2012; 62(595): e113-20. PMid:22520788 https://doi.org/10.3399/bjgp12X625175

[8] Rosenberg T. Acute hospital use, nursing home placement, and mortality in a frail community-dwelling cohort managed with Primary Integrated Interdisciplinary Elder Care at Home. J Am Geriatr Soc. 2012; 60(7): 1340-6. PMid:22694020 https ://doi .org/10.111 $1 / j .1532-5415.2012 .03965 . x$

[9] Miller P, et al. Economic analysis of an early discharge rehabilitation service for older people. Age Ageing. 2005; 34(3): 274-80. PMid:15764621 https://doi.org/10.1093/ageing/afi058

[10] Rytter L, et al. Comprehensive discharge follow-up in patients' homes by GPs and district nurses of elderly patients. A randomized controlled trial. Scand J Prim Health Care. 2010; 28(3): 146-53. PMid:20429738 https://doi.org/10.3109/02813431003764 466

[11] Beland F, et al. A system of integrated care for older persons with disabilities in Canada: results from a randomized controlled trial. J
Gerontol A Biol Sci Med Sci. 2006; 61(4): 367-73. PMid:16611703 https://doi.org/10.1093/gerona/61.4.367

[12] Beland F, et al. Integrated services for frail elders (SIPA): a trial of a model for Canada. Can J Aging. 2006; 25(1): 5-42. PMid:16770746 https://doi.org/10.1353/cja.2006.0019

[13] Walker L, Jamrozik K. Effectiveness of screening for risk of medical emergencies in the elderly. Age Ageing. 2005; 34(3): 238-42. PMid:15764623 https://doi.org/10.1093/ageing/afi055

[14] Rosted E, et al. Testing a two step nursing intervention focused on decreasing rehospitalizations and nursing home admission post discharge from acute care. Geriatr Nurs. 2013; 34(6): 477-85 PMid:24041934 https://doi.org/10.1016/j.gerinurse. 20 13.08 .001

[15] Meisinger C, et al. Effects of a nurse-based case management compared to usual care among aged patients with myocardial infarction: results from the randomized controlled KORINNA study. BMC Geriatr. 2013; 13: 115. PMid:24168465 https://doi .org/10.1186/ 1471-2318-13-115

[16] Bergman H, et al. Care for Canada's frail elderly population: Fragmentation or integration? CMAJ: Canadian Medical Association Journal. 1997. 157(8): 1116-1121. PMid:9347783

[17] Hansen MB, Vedung E. Theory-Based Stakeholder Evaluation. American Journal of Evaluation. 2010; 31(3): 295-313. https ://doi . or $\mathrm{g} / 10.1177 / 1098214010366174$

[18] Morgan DL. Focus Groups as Qualitative Research. Qualitative Research Methods Series 16. Vol. Second. 1997, Thousand Oaks, California SAGE Publications Inc.

[19] O'Brien BC, et al. Standards for reporting qualitative research: a synthesis of recommendations. Acad Med. 2014; 89(9): 1245-51. PMid:24979285 https://doi.org/10.1097/ACM. 0000000000 000388

[20] Boll HE. Midlertidige plejeformer mellem hjemmepleje og sygehus-erfaringer fra England [Intermediate care between home and hospital- Lessons from England], KORA, Editor. 2014. 